http://dx.doi.org/10.18675/1981-8106.vol24.n45.p57-75

\title{
Relações raciais e de gênero: a educação física escolar na perspectiva da alquimia das categorias sociais
}

\author{
Luciano Nascimento Corsino \\ Universidade Federal de São Paulo, São Paulo - Brasil \\ lucianocorsino@yahoo.com.br \\ Daniela Auad \\ Universidade Federal de Juiz de Fora, Minas Gerais -Brasil \\ auad.daniela@gmail.com
}

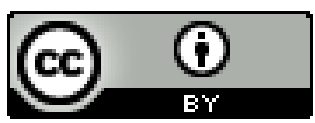

Educação: teoria e prática, Rio Claro, SP, Brasil - elSSN: 1981-8106

Está licenciada sob Licença Creative Common

\section{Resumo}

O artigo apresenta argumentos para a discussão de uma pesquisa realizada em Escola Pública, evidenciando as identidades produzidas e reveladas pela rica mistura das especificidades das categorias sociais no âmbito das aulas de Educação Física. Nessas, assim como em outras situações escolares, as diferenças hierarquizadas estão intrinsecamente relacionadas aos conflitos raciais e ao modo como as/os professores lidam, usualmente de modo desigual, com alunos e alunas. As formas como os/as docentes separam ou misturam meninas e meninos e como sistematizam e escolhem temas e conteúdos revelam a importância do debate tanto da heteronormatividade quanto da exaltação de determinada raça/etnia em detrimento de outras. Assim, ao pensar, como pano de fundo, no ardente culto aos privilégios heterossexuais e na negação da negritude, o texto propõe reflexões que abordam tanto gênero quanto raça como categorias que estão intrinsecamente relacionadas e que se tornam emergentes nas políticas educacionais e nas práticas pedagógicas, a partir de imbricado feixe de categorias sociais.

Palavras-chave: Educação Física Escolar. Política educacional. Relações de gênero.

Relações raciais.

\section{Race relations and gender: school physical education from the perspective of the alchemy of social categories}

\section{Abstract}

The article presents arguments for a discussion of a research conducted in Public School, showing the identities produced and developed by the rich mix of specific 
social categories within the PE lessons. In these, as in other school situations, hierarchical differences are intrinsically related to race riots and how teachers deal usually unevenly, with students. The ways the teachers separate or mixed girls and boys and how to systematize and choose themes and contents reveal the importance of the debate either of heteronormativity as the exaltation of a particular race ethnicity over others. So, to think, as a backdrop, the ardent worship of heterosexual privilege and denial of blackness, the text proposes reflections addressing race as well as gender categories that are intrinsically linked and become emerging educational policies and the pedagogical practices from overlapping beam social categories .

Keywords: Physical Education. Education Policy. Gender Relations. Race Relations.

\title{
Relaciones raciales y de género: la educación física escolar en la perspectiva de la alquimia de las categorías sociales
}

\begin{abstract}
Resumen
El artículo presenta argumentos para la discusión de una investigación realizada en Escuela Pública, evidenciando las identidades producidas y reveladas por la rica mezcla de las especificaciones de las categorías sociales en el ámbito de las clases de Educación Física. En estas, así como en otras situaciones escolares, las diferencias jerarquizadas están intrínsecamente relacionadas a los conflictos raciales y al modo como los/las profesores lidian, usualmente de modo desigual, con alumnos y alumnas. Las formas como los/las docentes separan o mezclan niñas y niños y como sistematizan y escogen temas y contenidos revelan la importancia del debate tanto de la heteronormatividad, como de la exaltación de determinada raza/etnia en detrimento de otras. De este modo, al pensar, como paño de fondo, en el ardiente cultura a los privilegios heterosexuales y en la negación de la negritud, el texto propone reflexiones que abordan tanto género como raza como categorías que están intrínsecamente relacionadas y que se vuelven emergentes en las políticas educacionales y en las prácticas pedagógicas, a partir de un imbricado conjunto de categorías sociales.
\end{abstract}

Palabras clave: Educación Física Escolar, Política educacional. Relaciones de género. Relaciones raciales.

\section{Diferenças hierarquizadas e diversidade}

[...] falta ainda estimular debates mais ampliados na escola sobre perspectivas de políticas e programas pedagógicos em relação às crianças e aos jovens, considerando sua diversidade e as desigualdades, segundo raça, gênero, classe e outras demarcações sociais. Cabe também refletir sobre como a escola lida e se 
prepara para a diversidade e colabora tanto para a formação de sujeitos de direitos, como se constitui em lugar de exercício de cidadanias, inclusive a étnicocultural e por gênero, considerando, insiste-se, singularidades de crianças e jovens. (CASTRO, 2008, p. 8).

Para o preenchimento das lacunas assinaladas pela citação acima, há de se perceber como as diferenças hierarquizadas são construídas mediante uma combinação da categoria gênero ora com raça, ora com geração, ora com classe social, ora com orientação sexual. Seja em uma perspectiva de intersecção, seja diante da noção de alquimia ${ }^{1}$ das categorias sociais (CASTRO, 1992), a perspectiva sobre a diversidade adotada no presente texto pode potencializar o debate, por exemplo, sobre como são construídas, mantidas ou eliminadas as desigualdades, com base na consideração de vulnerabilidades relacionadas às variadas maneiras de ser mulher e jovem, lésbica e negra, idosa e pobre. Cada uma dessas identidades e todas elas informam e conformam diferenciais de poder construídos em nossa sociedade. Essas diferenças hierarquizadas, usualmente, tornam as mulheres uma minoria social em relação aos homens, em variadas searas do cotidiano, como no mercado de trabalho e participação no poder. A maternidade, por exemplo, é algo que foi e é frequentemente oferecido como explicação para a exclusão das mulheres do mercado de trabalho e da participação política. Da mesma maneira, a raça foi historicamente relacionada à razão da escravização e/ou sujeição das mulheres negras. Nesses casos, os processos de diferenciação social baseados em gênero e raça produzem exclusões as quais são, então, justificadas em termos percebidos como biológicos (SCOTT, 2005).

Há de se sublinhar que, na presente abordagem sobre diversidade, as relações de gênero são centrais e correspondem ao conjunto de representações construído em cada sociedade, com sua história, para se atribuírem significados, símbolos e diferenças desiguais para cada um dos sexos. As características biológicas atribuídas aos homens e às mulheres são interpretadas segundo as construções de gênero de

\footnotetext{
${ }^{1}$ A palavra alquimia é adotada no presente texto, inicialmente, por força da citação do texto de Mary Castro, intitulado Alquimia das categorias sociais na produção dos sujeitos políticos (1992). Tal adoção é potencializada e fundamentada pela ideia de mistura de elementos que, ao ocorrer, transforma cada um deles, de modo a torná-los diferentes do que eram originalmente, antes de se terem misturado. Para mais referências sobre esse entendimento do termo alquimia, sobre a definição de mistura e sobre o conceito de "mixité", pesquisar em Zaidman (1996, 2002), Hirata (2000), Auad (2004, 2006).
} 
cada sociedade. Em outras palavras, o gênero faz com que percebamos o sexo biológico, pois as características e diferenças anatômicas são enxergadas e valorizadas do modo como são, e não de outro modo, graças à existência das relações de gênero socialmente construídas. Repetidamente praticadas, contadas e recontadas, essas relações vão ganhando a feição de "naturais". Tais características são construídas historicamente, devido ao modo como as relações de poder entre alguns pares foram e vão se engendrando socialmente (AUAD, 2006).

Negritude e branquitude, juventude e velhice, riqueza e pobreza, heterossexualidade e homossexualidade são pares comumente utilizados para revelar, produzir e para analisar os fenômenos sociais, ao lado dos e em conjunto com os arranjos de gênero também polarizados entre masculino e feminino. Relacionado a essas combinações, um vasto conjunto de ideias e representações cria percepções binárias e naturalizadas, as quais serão utilizadas para "organizar" os sujeitos de modo a reforçar diferenças hierarquizadas, em uma desigual escala de valores. Essas dinâmicas e processos tornam as mulheres sujeitas a vulnerabilidades específicas, as quais correspondem a um conjunto de fatores cuja interação amplia ou reduz o risco ou a proteção de uma pessoa ou de uma população em relação a uma determinada doença, condição ou dano. Assim, ser menina adolescente, negra, homossexual e moradora da periferia é um exemplo de como as vulnerabilidades podem se somar e representar obstáculos ao pleno desenvolvimento de um grupo populacional, causando, em última análise, e em longo prazo, um dano imenso à construção de uma sociedade que se pretende igualitária e democrática.

Na mesma perspectiva de análise desse fenômeno, atualmente é possível perceber um grande movimento voltado à eliminação das mais diversas hierarquizações sociais presentes em nossa sociedade. No Brasil, o colonialismo foi um período responsável pela criação de profundas desigualdades raciais; na sequência, as teorias racialistas acabaram por justificar as ações colonialistas, que ainda estão presentes nas relações sociais, mesmo que de forma velada. Após a Segunda Guerra, muitos movimentos institucionais, como o da UNESCO, que resultou na reescrita da História da África, se debruçaram sobre essa temática e se organizaram tendo como principal objetivo a eliminação das profundas desigualdades raciais existentes em nossa sociedade. 
Na América, engendraram-se alguns movimentos como o Pan-africanismo e a Consciência Negra, que foram cruciais para a contestação ideológica do colonialismo. Apesar de terem surgido em países da América, esses movimentos se disseminaram por toda a Europa e resultaram em consideráveis mudanças políticas e sociais na luta contra a hegemonia europeia.

No Brasil, diversas pesquisas passaram a analisar e denunciar os livros didáticos, que, até então, não correspondiam à realidade dos/as alunos/as, apresentando problematizações e imagens eurocêntricas, e desconsideravam a história e a cultura afro-brasileira. O tratamento preconceituoso e a ausência de conteúdos relacionados à história e à cultura afro-brasileira são características responsáveis por produzir alunos/as desestimulados/as e, consequentemente, por diminuir as possibilidades de uma aprendizagem significativa (MUNANGA, 2001).

Como reflexo dessas lutas, foi apenas no ano de 2003 que se promulgou a Lei 10.639/03, responsável por alterar a Lei de Diretrizes e Base da Educação Nacional 9.394/96. De acordo com a publicação (BRASIL, 2010), “os conteúdos referentes à História e Cultura Afro-Brasileira serão ministrados no âmbito de todo o currículo escolar, em especial nas áreas de Educação Artística e de Literatura e História Brasileira". Nesse sentido, a Lei propicia e fundamenta, no caso da Educação Física, o tratamento de temas como a Capoeira e as Danças Afro-Brasileiras, fato que representou inegável avanço nas políticas educacionais em nosso país, no que diz respeito à abordagem de temas relacionados às minorias sociais.

Assim como ocorreu com as questões étnico-raciais, as relações de gênero também tiveram um percurso marcado por lutas travadas pelos movimentos sociais nas variadas searas da sociedade. Na Educação, apesar da existência de trabalhos dedicados às relações de gênero, foi a partir do ano de 1990, com a chegada do artigo "Gênero: uma categoria útil de análise histórica" da pesquisadora americana Joan Scott, que houve uma considerável difusão de pesquisas nos diferentes setores relacionados à Educação.

A Educação Física foi uma das áreas que adotou o gênero como uma categoria possível para análise das construções das diferenças hierarquizadas. Esses estudos (SOUSA, 1994; ALTAMNN, 1998; SARAIVA 2005; CORSINO, 2011 e outras) foram responsáveis por denunciar as diversas práticas hierarquizadas no interior da escola, 
apontando a emergência de uma prática pedagógica com intencional e sistematizada ação na direção da igualdade de gênero, ou, em outras palavras, uma educação coeducativa (AUAD, 2004).

\section{Relações raciais e de gênero na Educação Física Escolar}

Atualmente, o debate acerca das relações de gênero na Educação Física Escolar encontra-se em crescimento, permeando e promovendo uma intersecção entre diversas temáticas, como corpo, raça, mídia, esporte, lazer e sexualidade, consideradas locus de pesquisa e intervenção pedagógica. No entanto, não é o que parece quando pensamos sobre a temática racial na Educação Física Escolar.

Corsino e Auad (2011) realizaram análise em dois periódicos científicos avaliados na área da Educação Física. Foram levantados todos os artigos publicados entre os anos de 2003 e 2011, a fim de identificar os trabalhos que abordam essa temática. Diante dos dados inicialmente coletados, o autor e a autora apontaram que parece haver necessidade de estudos que contemplem a relação entre gênero e raça, considerando-se que a formação do sujeito político é permeada por essas categorias sociais.

Como desfecho do trabalho, Corsino e Auad (2011, p. 6) levantaram os seguintes questionamentos: Por que parece se considerar menos raça do que gênero e, ainda assim, por que gênero é tão pouco adotado nos estudos? Esse debate converge em pesquisa sobre as causas das múltiplas invisibilidades, considerando-se, sobretudo, que raça ainda é um tema menos estudado e problematizado na Educação Física Escolar do que gênero². Sendo assim, há de se questionar os motivos da desconsideração de ambas as categorias, tanto em conjunto quanto isoladamente.

Jesus (2008) apresenta fatos explícitos de racismo ${ }^{3}$ no esporte contemporâneo. Após a descrição das situações de racismo, o autor aponta os seguintes questionamentos:

\footnotetext{
${ }^{2}$ O trabalho citado pode ser encontrado nos anais do XI Congresso Luso-Afro Brasileiro de Ciências Sociais, realizado no ano de 2011, disponível no site http://www.xiconlab.eventos.dype.com.br ${ }^{3}$ Segundo Cavalleiro (2000), o racismo é produto de uma construção histórica, iniciada no século XIX, a partir das teorias evolucionistas, que foram responsáveis por influenciar diversas áreas do conhecimento, como a Biologia e as Ciências Sociais. O racismo é uma ideologia que opera por meio de relações de poder e é responsável pela dominação de um grupo sobre o outro, a partir da atribuição de características negativas ao grupo considerado inferior.
} 
Por que ainda presenciamos situações de racismo na sociedade? Por que apesar de todas as atrocidades que as teorias racialistas já promoveram para a humanidade, ainda são presentes e ressignificadas? Qual o papel do profissional de Educação Física sobre esse fato? Está sendo oferecido o conhecimento sobre cultura africana e afro-brasileira nas escolas básicas brasileiras? O currículo de Educação Física escolar atende as diretrizes da Lei 10.639/03? (JESUS, 2008, p. 172).

Ao acreditar na possibilidade de professoras e professores de Educação Física engendrarem o debate acerca do racialismo a partir da lei 10.639/03, o autor apresenta a "origem da teoria do racismo na sociedade francesa entre os séculos XVII e XIX" (p. 172). Para ele, é importante que os/as professores/as conheçam a história do pensamento sobre a diversidade humana, tendo em vista que até hoje sofremos suas consequências.

Ao tratar das relações de gênero nas aulas de Educação Física, Sousa e Altmann (1999) apontam que, apesar de atualmente o esporte ser apresentado como uma prática para homens e mulheres, independentemente da modalidade, ainda é pautado pelas relações de gênero desiguais e, portanto, é responsável por grande parte da construção das diferenças hierarquizadas no âmbito da Educação Física Escolar, considerando-se variáveis como sexo, força, idade e habilidade.

Em relação às formas de organização das aulas de Educação Física, no que se refere à constituição de turmas separadas por sexo, Dornelles e Fraga (2009) analisam as várias formas de separação no interior das aulas. Nesse sentido, os/as autores/as indicam a necessidade de um olhar mais aprofundado sobre as formas de organização em relação aos/as alunos/as, sem se desprezarem as separações como uma forma possível de configuração das relações de gênero, tendo em vista que, para eles/as, as turmas mistas, por si só, não garantem o término das hierarquizações. Segundo Auad (2004), a escola mista não garante a existência da coeducação. A autora distingue termos que são utilizados comumente como sinônimos para sublinhar a mistura de sexos já existente, mas que, com as relações hierárquicas entre os masculinos e os femininos, acabam por acirrar as desigualdades de gênero. 
Ao se apoiar nos Estudos Culturais e de Gênero, os/as pesquisadores/as Neira, Santos Júnior e Santos (2009) ressaltam como a mídia, principalmente a televisiva, pode construir a noção de feminilidade por meio dos discursos empreendidos cotidianamente. Nesse sentido, os/as autores/as entendem a Educação Física Escolar como uma disciplina que pode promover ações pedagógicas, no sentido de proporcionar aos/as alunos/as uma reflexão crítica, de modo que haja um olhar cuidadoso sobre o que é apresentado como um corpo feminino na TV, favorecendo um processo de desconstrução das ideias impostas como verdadeiras. Nessa perspectiva, o presente texto parte do princípio da comunicação como elemento central na sociedade contemporânea e da percepção da mídia como espaço público. Na mídia, identidades são configuradas e reconfiguradas, uma vez que se trata de instância responsável pelas mediações sociais, tanto como reguladora da relação do indivíduo com o mundo e com seus pares, quanto como agência socializadora (LAHNI e AUAD, 2012).

Em relação à Educação Física Escolar no Ensino Fundamental I, Gomes, Moreno e Altmann (2013) realizaram uma análise da produção acadêmica, com base em um levantamento de teses e dissertações em diversas Universidades do país. O objetivo principal foi identificar os estudos que se dedicaram a investigar as relações de gênero nessa modalidade de ensino, contemplando alunos/as em uma faixa etária de 7 a 10 anos de idade. Após o levantamento, as autoras encontraram apenas 5 trabalhos relacionados ao tema. Nesse sentido, a pesquisa indica pouca produção acerca das relações de gênero no Ensino Fundamental I e, ainda, aponta que os estudos analisados pressupõem uma ênfase muito maior no que diz respeito aos jogos e esportes, não contemplando outras manifestações da Cultura Corporal, como a luta, a dança e a ginástica.

Pereira (2009) analisou as relações de gênero presentes em aulas em que os temas eram a dança e o futebol e concluiu que as desigualdades estão presentes em ambas as manifestações. Baseado em manifesta inspiração na obra de Paulo Freire, o autor ressalta a importância do diálogo com alunos e alunas de forma a se considerar as relações de gênero, destacando a dança e o futebol como temas privilegiados para uma problematização que se direcione para práticas igualitárias. 
Ao se debruçar sobre os sentidos de gênero nas aulas de Educação Física em turmas de Ensino Fundamental I, Fernandes (2008) constatou que as turmas de 1a e $2 \underline{a}$ série estavam, no seu campo de pesquisa, marcadas pelos binarismos, fundamentado em um sistema heteronormativo. Nesse sistema, ao mesmo tempo em que certas normas são ditadas, são abertos espaços para relações espontâneas, que cruzam as fronteiras estabelecidas e borram os limites do que é percebido como masculino e como feminino.

Tal tensão é analisada por Auad (2004), ao descrever o que define como "aprendizado da separação". Em sua pesquisa sobre relações de gênero no Ensino Fundamental, em escola pública do município de São Paulo, Auad constatou o que outras pesquisadoras haviam afirmado tanto para a realidade brasileira, como Guacira Lopes Louro (1997, 2001), quanto para a conjuntura internacional, como Marina Subirats Martori (1998) e Claude Zaidman (1996, 2002). As autoras citadas percebem as muitas maneiras como as relações durante as aulas se dão por meio de complexas relações de poder a partir das identidades dos sujeitos em interação. Auad, em seu campo, a Escola do Caminho, considerou que as professoras potencializavam as diferenças hierarquizadas entre meninas e meninos, reforçando habilidades "das" meninas e outras "dos" meninos, de modo a estimular uma interiorização das expectativas do que é mais adequado aos meninos e, em oposição, do que é propício às meninas. Havia, por exemplo, crianças que cruzavam as fronteiras estabelecidas, porém, eram vistas como meninas e meninos que saíam dos padrões, como um desvio, ou seja, como um caso que necessitaria de atenção individual, pois tais transgressões eram consideradas problemas.

Devido a essas constatações, percebe-se a importância de se considerar o corpo também como uma construção que sofre a influência das relações de gênero e é constituído, constantemente, por elas. Nessa perspectiva, há a necessidade de se analisar e questionar como são as construções dos corpos nas misturas e separações da Educação Física, com o intuito principal de direcionar para uma Educação Física Escolar Coeducativa (CORSINO e AUAD, 2012).

Para Saraiva (2002), as práticas coeducativas na Educação Física Escolar apontam para resultados satisfatórios no que diz respeito à diminuição e eliminação 
das práticas hierarquizadas no Esporte e no Lazer, fato que enfatiza a necessidade de ações pedagógicas que considerem as relações de gênero.

Nessa perspectiva, uma Educação Física Escolar Coeducativa promoveria a igual valorização do que é percebido como masculino e como feminino, assim como a consideração da existência de diferentes masculinos e diferentes femininos, todos eles passíveis de mérito e de valorização em variados contextos. Tal projeto igualitário tornaria as vivências corporais não enclausuradas no âmbito do que é ideal para meninos e para meninas, no que é aceito como habilidade e como competência para cada um dos sexos. Trata-se de uma perspectiva na qual a noção de habilidade é também desconstruída e, a partir disso, paradigmas e práticas da área de Educação Física Escolar são questionados.

Do ponto de vista metodológico, ao se considerar gênero como uma categoria de análise, pretendeu-se desenvolver um olhar com o qual se penetra no campo com o intuito de decifrar códigos, "ler entrelinhas, perceber comportamentos, 'pescar' discursos e falas, interpretar significados, enfim, filtrar o dito e o não dito pelos atores sociais no que se refere à problemática de algum estudo." (OLIVEIRA; DAOLIO, 2007, p. 141).

Nesse sentido, foi realizada uma investigação de inspiração etnográfica (ANDRÉ, 1995) em aulas de Educação Física, que abrangeu turmas de 5a , 6a e 7ạ séries do Ensino Fundamental II, em escola da rede estadual de São Paulo e conheceu a prática pedagógica de professores e professoras a partir do olhar sobre como as relações de gênero eram percebidas, silenciadas, orientadas, invisibilizadas e/ou problematizadas. Para a coleta de dados, foi utilizada a técnica de observação, que ocorreu em um diário de campo, um instrumento em que se anotam todos os diversos momentos da pesquisa da forma mais completa e precisa possível (TURA, 2003).

Durante as oitenta horas de observação, foram elaboradas resenhas, a fim de contextualizar e problematizar os dados coletados, relacionando-os com as discussões disponibilizadas por um aprofundamento da revisão de literatura.

\section{Alquimia das categorias sociais por uma leitura igualitária da escola}

Da forma de organização de alunas e alunos nas aulas até a escolha dos temas e conteúdos a serem abordados durante o período letivo, as questões de gênero e de 
raça são emergentes na constituição das identidades de meninas e meninos no interior da escola, e estão inter-relacionadas.

Até o modo de se vestir para a prática da Educação Física pode ser reflexo de um cotidiano marcado pelas relações de poder, que produzem diferentes sentidos, gostos e necessidades. Como é possível perceber em descrição realizada por Corsino:

Em todas as aulas observadas, os rituais eram os mesmos: meninas e meninos entravam na sala de aula, o professor realizava a chamada e, logo em seguida, verificava quais alunos/as estavam vestidos/as com trajes inadequados para as vivências práticas (geralmente, calça jeans ou sandálias) e anotava no diário de classe, com exceção dos dias em que as aulas seriam teóricas. É interessante notar que, durante muitos momentos, foi possível perceber alunas que compareciam às aulas com vestimenta inadequada, intencionalmente, para não participar das vivências, alegando que não gostavam das atividades desenvolvidas na Educação Física. (2001, p. 100).

A discriminação racial nas relações entre meninos e meninas, meninas e meninas, meninos e meninos também é notória durante as aulas de Educação Física. Ao relatar sua percepção dos conflitos de gênero e raça durante as aulas, Corsino (2013, p. 28) apresenta relato de um professor de Educação Física de uma escola pública do município de Guarulhos, que indicou que há múltiplas hierarquizações durante as aulas, tanto de gênero como de raça, apontando a importância de se estabelecer um diálogo sobre os conflitos com alunos e alunas.

Professor 3: Sim, um chama o outro de preto, macaco, mulherzinha, falam que as meninas não sabem fazer nada, são fracas, etc. [...] Vejo essa questão como sendo um pouco complicada de fazer os alunos entenderem, na maioria das vezes eu paro a aula, faço uma roda de conversa, pergunto se é certo tal atitude, por que, faço eles dialogarem e discutirem a respeito, mas mesmo assim as vezes parece que isso não adianta.

Perceber os conflitos de gênero e raça durante as aulas de Educação Física pode ser um avanço no sentido de se tornarem visíveis as desigualdades que se 
impõem cotidianamente no interior da Educação Física, tendo em vista que um dos problemas recorrentes no que diz respeito às hierarquizações nas aulas de Educação Física passa pelo silenciamento, que muitas vezes é reforçado pelos/as professores/as (CORSINO, 2011), mas que, nesse caso, não ocorre com os/s professores/as participantes da pesquisa.

A situação descrita pelo autor sugere que o fato de a aluna não se vestir adequadamente para a aula de Educação Física resultaria na impossibilidade de participação da aula, e que a atitude da aluna foi intencional, pois ela não gosta das aulas pelo fato de que os conteúdos e temas abordados, como o futebol, são percebidos como seara dos meninos. Essa atitude pode indicar uma forma de resistência aos conteúdos construídos e percebidos, historicamente, como masculinos ou femininos, apontando para a necessidade de diversificação das atividades trabalhadas, ao longo do ano letivo.

Raça e gênero são, assim, categorias constitutivas dos sujeitos e das interações que são estabelecidas nas instituições e que, ao se travarem, as constroem no conjunto das práticas escolares. Essas categorias exerceram importante papel na constituição dos elementos culturais da Educação Física Escolar, tais como o Esporte, o Jogo, a Ginástica, a Brincadeira, a Luta e a Dança. Nesse sentido, as práticas que ditam o que é masculino ou feminino, como o balé para as meninas e o futebol para os meninos, estão constantemente configurando e reconfigurando esses elementos, que, embora pareçam padronizados, não são fixos ou estáveis e, portanto, são passíveis de transformação.

Um exemplo disso é a forma como os quatro professores organizavam suas aulas, sendo que três deles separavam meninas e meninos, ora dividindo a quadra ao meio, ora dividindo o tempo para cada grupo de alunas e alunos. A prática de separação entre meninas e meninos é motivada pela falsa sensação de igualdade e, principalmente, pelo pretendido silenciamento dos conflitos de gênero:

As relações de gênero nas aulas de Educação Física da Escola do Princípio constroem falsas representações em discentes e docentes de que as turmas separadas, apesar de estarem dentro do mesmo horário e espaço, são melhores para a organização, socialização e rendimento das aulas. Estas práticas geram uma 
forma de silenciamento dos conflitos. Apesar de separar as turmas por sexo, os professores não conseguiam fugir dos conflitos. [...] Tal fato, consequentemente, desconsiderava as diferenças, impondo uma falsa sensação de igualdade. (CORSINO, 2011, p. 130).

Ao observar os temas trabalhados durante as aulas investigadas, Corsino (2011) relata que percebeu que as aulas de Educação Física na escola pesquisada são organizadas segundo três modalidades esportivas coletivas e uma individual. Para o autor, o desenvolvimento de todas essas modalidades apresentou inegável aumento das hierarquizações de gênero nas aulas de Educação Física:

O que se pode compreender é que o tratamento dos conteúdos, muito pouco ou nada, se relacionava com as construções de gênero elaboradas no cotidiano das aulas observadas. Ao contrário, a forma como os conteúdos eram tratados se encaminhava num sentido de potencializar as diferenças hierarquizadas naquele ambiente. Os temas propostos não fugiam do esporte, e as formas como as modalidades esportivas eram tratadas não iam ao encontro de uma Educação Física Escolar Coeducativa. (CORSINO, 2011, p. 131).

Os temas trabalhados durante as aulas pouco se relacionavam com as proposições do Currículo da Rede Estadual, que era o documento responsável por direcionar o planejamento docente e apresentava diversas possibilidades de tratamento dos elementos culturais nas aulas de Educação Física:

Durante a maioria das aulas observadas, não foi possível perceber o tratamento da Proposta Curricular do Estado de São Paulo - Educação Física, documento responsável por nortear as ações docentes. Com exceção de um professor que trabalhou o Atletismo, os outros utilizaram os conteúdos sugeridos pelo documento apenas como uma forma de solicitar trabalhos e pesquisas. (CORSINO, 2011, p. 130).

Entende-se, porém, que a utilização do Currículo poderia contribuir fortemente com a diversificação de conteúdos, fato que seria de considerável relevância para a 
problematização das relações étnico-raciais e de gênero. O documento, de fato, oferece temas que se relacionam diretamente com essas categorias sociais, como danças regionais, capoeira e outros elementos.

Ao final, constatou-se que as aulas de Educação Física, da maneira como são conduzidas no campo pesquisado, oferecem diversas práticas hierarquizantes, tanto de gênero como de raça. Nas aulas em que as turmas eram separadas, os conflitos apareciam de forma velada, mas não desapareciam. Por outro lado, nas aulas em que as turmas eram misturadas, os conflitos eram explícitos e prejudicavam seu andamento.

Segundo Corsino (2011), ao contrário das aulas "misturadas", em que os conflitos apareciam a partir de agressões verbais e físicas, nas aulas em que as turmas eram separadas os conflitos eram velados. Na prática do futebol, por exemplo, raramente era possível observar agressões físicas ou verbais, no entanto, alguns meninos excluíam os colegas, como foi o caso do menino que privou o colega de jogar, alegando que ele era uma "bicha". Entende-se, apesar disso, que as aulas misturadas, apesar de não oferecerem a coeducação em determinados momentos, representam um dos caminhos para tal.

Os temas trabalhados reforçavam as desigualdades raciais e de gênero durante as aulas e não contemplaram as orientações do Currículo do Estado de São Paulo, que estabelece para a disciplina de Educação Física uma perspectiva "culturalista", ou seja, apresenta uma concepção baseada em perspectivas oriundas das Ciências Humanas e Sociais (BETTI et al., 2010). A Proposta apresenta uma dinâmica cultural na qual se insere a cultura de movimento, representada pelos esportes, danças, artes marciais/lutas, ginásticas e pelos exercícios físicos. Compreende, também, a importância de se considerarem as culturas juvenis, as quais mostram que os adolescentes possuem afinidades com determinadas manifestações da cultura de movimento, como o hip-hop, a capoeira, as artes marciais, o skate, a musculação e outros (SÃO PAULO, 2008).

[...] a Educação Física trata da cultura relacionada aos aspectos corporais, que se expressa de diversas formas, dentre as quais os jogos, a ginástica, as danças e atividades rítmicas, as lutas e os esportes. Essa variabilidade dos fenômenos 
humanos ligados ao corpo e ao movimentar-se é ainda mais importante quando se pensa na pluralidade dos modos de viver contemporâneos. (SÃO PAULO, 2008, p. 42).

Como é possível notar, o Currículo Paulista oferta a possibilidade de trabalho com temas diversificados e, portanto, pode viabilizar a consideração igualitária do referencial de gênero e da abordagem das questões raciais, pelo menos no tocante à Educação Física.

Considerar raça e gênero como categorias a partir das quais são tecidas identidades dos indivíduos e dos grupos, como instâncias e searas de exercício igualitário da cidadania, como suscita a leitura de Joan Scott, em seu Enigma da Igualdade (2005), concorre para a reflexão sobre como cada uma das identidades e todas elas informam e conformam diferenciais de poder construídos em nossa sociedade. Em uma perspectiva desigual do ponto de vista das relações raciais e de gênero, atributos ligados ao feminino, como a maternidade, por exemplo, foram - e ainda são - frequentemente oferecidos como explicação para a exclusão das mulheres do mercado de trabalho e da participação política. Da mesma maneira, a raça foi historicamente relacionada à razão da escravização e/ou sujeição das mulheres negras. Nesses casos, os processos de diferenciação social baseados em gênero e raça produzem exclusões as quais são justificadas em termos percebidos como biológicos (SCOTT, 2005). A sub-representação das meninas e mulheres no futebol, apesar da existência da icônica Marta ${ }^{4}$, assim como o desempenho abaixo do que conhecemos como possível dos meninos, na dança, são fenômenos que podem ser resultantes de processos de diferenciação social hierarquizada, iniciados nas quadras das escolas e nos pátios, durante os recreios.

As considerações tecidas ao longo do presente artigo, com base na análise de dados de campo e de estudo bibliográfico, pretendem concorrer para não mais se atrelar as múltiplas diferenças dos grupos e dos indivíduos a argumentos que possam

\footnotetext{
${ }^{4}$ Marta Vieira da Silva é jogadora de futebol de destaque internacional, com atuação vitoriosa em clubes do Brasil, Europa e Estados Unidos, atualmente é atleta do Tyresö FF, da Suécia. Marta possui premiações internacionais, com destaque para o prêmio de melhor jogadora do mundo nos anos de 2006, 2007, 2008, 2009 e 2010, em evento organizado pela Fédération Internationale de Football Association (FIFA).
} 
justificar e cristalizar as separações e diferenças hierarquizadas. Assim, se pretende contribuir para que meninas, meninos, negras e negros estejam misturados na escola, em contexto coeducativo igualitário, a começar pelas aulas de Educação Física, de modo que possam integrar-se à coletividade sem que suas individualidades e especificidades sejam invisibilizadas.

\section{Referências}

ANDRÉ, Marli Eliza D. A. Etnografia da prática escolar. Campinas: Papirus, 1995.

AUAD, Daniela. Relações de gênero nas práticas escolares: da escola mista ao ideal de coeducação. 2004. 232f. Tese (Doutorado em Educação: Sociologia da Educação) Faculdade de Educação, Universidade de São Paulo, São Paulo, 2004.

. Educar meninos e meninas: relações de gênero na escola. São Paulo: Editora Contexto, 2006.

BETTI, Mauro et al. A proposta curricular de educação física do Estado de São Paulo: fundamentos e desafios. In: CARREIRA FILHO, Daniel; CORREIA, Walter Roberto. Educação física escolar: docência e cotidiano. Curitiba: CRV, 2010.

BRASIL. Lei no. 10.639 de 09 de janeiro de 2003. Inclui a obrigatoriedade da temática História e Cultura Afro-Brasileira no currículo oficial da rede de ensino. Diário Oficial da União, Brasília, 2003.

CAVALLEIRO, Eliane. Do silêncio do lar ao silêncio escolar: racismo, preconceito e discriminação na educação infantil. São Paulo: Contexto, 2000.

CORSINO, Luciano Nascimento. As relações raciais e de gênero na concepção de professoras e professores de Educação Física da Prefeitura de Guarulhos. 2013. 35 f. Trabalho de Conclusão de Curso (Especialização em Educação para as Relações ÉtnicoRaciais) - Universidade Federal de São Carlos, São Carlos, 2013.

Relações de gênero na Educação Física Escolar: uma análise das misturas e separações em busca da coeducação. 2011. 154f. (Mestrado em Ciências: Educação e Saúde na Infância e na Adolescência) - Escola de Filosofia, Letras e Ciências Humanas, Universidade Federal de São Paulo, Guarulhos, 2011.

CORSINO, Luciano Nascimento; AUAD, Daniela. O professor diante das relações de gênero na educação física escolar. São Paulo: Cortez, 2012.

. Raça e gênero na Educação Física Escolar: uma análise da produção científica a

partir da lei 10.639/03. In: XI CONGRESSO LUSO AFRO BRASILEIRO DE CIÊNCIAS 
SOCIAIS, 2011, Salvador/BA. Anais eletrônicos. Salvador: Universidade Federal da Bahia, 2011. Disponível em: <http://www.xiconlab.eventos.dype.com.br>. Acesso em 23 set. 2011.

CASTRO, Mary Garcia. Alquimia de categorias na produção dos sujeitos políticos: gênero, raça e geração entre os líderes do Sindicato dos Trabalhadores Domésticos em Salvador. Revista Estudos Feministas, Rio de Janeiro, n.ㅇ 0, 1992. Disponível em http://www.scielo.br. Acesso em: 16 dez. 2010.

Gênero e Raça: Desafios à Escola. Versão on line: http://www.smec.salvador.ba.gov.br/documentos/genero-raca.pdf. Acesso em 15 de jun. 2008.

DORNELLES, Priscila Gomes; FRAGA, Alex Branco. Aula mista versus aula separada? Uma questão de gênero recorrente na educação física escolar. Revista Brasileira de Docência, Ensino e Pesquisa em Educação Física. Cristalina, v. 1, n. 1, p. 141-156, ago/set. 2009.2 Disponível em: <http://www.facec.edu.br/seer/index.php/index/index.> Acesso em: 15 mar. 2011.

FERNANDES, Simone Cecilia. Os sentidos de gênero em aulas de Educação Física. 2008. 116f. Dissertação (Mestrado em Educação Física) - Faculdade de Educação Física, Universidade Estadual de Campinas, Campinas, 2008.

GOMES, Nathalia Chaves; MORENO, Marcia Orlando; ALTMANN, Helena. As relações de gênero no ensino fundamental I: uma análise da produção acadêmica em Educação Física. Conexões, Campinas, v. 10, n. 3, p. 142-171, set./dez. 2013.

HIRATA, Helena; LABORIE, Françoise; LE DOARÉ, Hélène; SENOTIER, Danièle. (coordenation). Dictionnaire Critique du Féminisme. Paris: Presse Universitaire de France, 2000.

JESUS, Marcelo Siqueira de. A dialética da teoria racialista como saber para problematizar em pesquisas sobre questões raciais no campo da educação física escolar. Motrivivência. Ano XX, $\mathrm{n}^{\circ}$ 30, Junho, 2008. Disponível em: http://www.periodicos.ufsc.br/index.php/motrivivencia. Acesso em: 02 abr 2011.

LAHNI, Cláudia Regina; AUAD, Daniela. Comunicação na perspectiva da igualdade de gênero: apontamentos para o debate sobre Marco Regulatório. In: BRITTOS, Valério Cruz; LOPES, Ruy Sardinha (Orgs.). Políticas de comunicação e sociedade. São Paulo: INTERCOM, 2012, p.307-334.

LOURO, Guacira Lopes. Gênero, sexualidade e educação: uma perspectiva pósestruturalista. Petrópolis, Rio de Janeiro, Vozes, 1997.

(Org.). O corpo educado: pedagogias da sexualidade. Belo Horizonte, Autêntica, 2001 ( $2^{\text {a }}$ edição). 
MUNANGA, K. Apresentação. In: MUNANGA, K (org.). Superando o racismo na escola. Brasília: Ministério da Educação, Secretaria de Educação, 2001.

NEIRA, Marcos Garcia.; SANTOS JUNIOR, Nei Jorge dos.; SANTOS, Ana Paula da Silva. Corpo Feminino na TV: reflexões necessárias no âmbito da educação física escolar. Conexões, Campinas, v. 7, n. 2, p. 97-113, maio/ago. 2009.

OLIVEIRA, Rogério Cruz de; DAOLIO, Jocimar. Pesquisa Etnográfica em Educação Física: uma (re)leitura possível. Revista Brasileira de Ciência e Movimento, v.15 n. 1, p. 137143, jul. 2007. Disponível em: <http://portalrevistas.ucb.br/.> Acesso em: 25 abr. 2011.

PEREIRA, Fabio Alves do Santos. Currículo, Educação Física e diversidade de gênero. 2009. 198f. Dissertação (Mestrado em Educação: Currículo) - Faculdade de Educação, Pontifícia Universidade Católica de São Paulo, São Paulo, 2009.

SÃO PAULO (Estado). Secretaria de Estado da Educação de São Paulo. Proposta Curricular do Estado de São Paulo: educação física - ensino fundamental ciclo II e ensino médio. São Paulo: SEE, 2008. Disponível em: <www.saopaulofazescola.gov.br>. Acesso em: 10 jun. 2013.

SARAIVA, Maria do Carmo. Coeducação física e esportes: quando a diferença é mito. 2. ed. ljuí: Unijuí, 2005.

SARAIVA, Maria do Carmo. Por que investigar as questões de Gênero no âmbito da Educação Física, Esporte e Lazer? Motrivivência, Florianópolis, no 19, p. 79-86, dezembro. 2002.

SCOTT, Joan Wallach. Gênero: uma categoria útil de análise histórica. Educação e Realidade. Porto Alegre, no 16, p. 5-22, 1990. p.11-30.

O Enigma da Igualdade. In: Revista de Estudos Feministas, Florianópolis, 2005,

SOUSA, Eustáquia Salvadora de; ALTMANN, Helena. Meninos e meninas: expectativas corporais e implicações para a educação física escolar. Cadernos Cedes, ano XIX, n. 48, 1999. Disponível em: <http://www.scielo.br>. Acesso em: 12 nov. 2009.

SOUSA, Eustáquia Salvadora de. Meninos, à marcha! meninas, à sombra!: a história do ensino da educação física em Belo Horizonte (1897-1994). 1994. 288f. Tese (Doutorado em Educação: Filosofia e História da Educação) - Faculdade de Educação, Universidade Estadual de Campinas, Campinas, 1994.

SUBIRATS, Marina. Educación de las mujeres: de la marginalidad a la coeducación: propuesta para una metodologia de cambio educativo. Santiago: Naciones Unidas/CEPAL, 1998. (Série Mujer y Desarrollo, 22). 
TURA, Maria de Lourdes Rangel. A observação do cotidiano escolar. In: ZAGO, Nadir.; CARVALHO, Marilia Pinto de.; VILELA, Rita Amélia Teixeira. (Orgs.). Itinerários de pesquisa: perspectivas qualitativas em Sociologia da Educação. Rio de Janeiro: DP\&A, 2003.

ZAIDMAN, Claude. La mixité à l'école primaire. Paris: L'Harmattan, 1996.

La mixité en questions: des résistances religieuses à la critique féministe, ou l'actualité de la question de la mixité scolaire. Raison Présente. Paris, Nouvelles Éditions Rationalistes, no 140, 2002.

Enviado em Julho/2013

Aprovado em Outubro/2013 